\title{
CCN: core regulatory proteins in the microenvironment that affect the metastasis of hepatocellular carcinoma?
}

\author{
Qingan Jia ${ }^{1,2}$, Qiongzhu Dong ${ }^{1}$ and Lunxiu Qin ${ }^{1,2}$ \\ ${ }^{1}$ Cancer Center, Institutes of Biomedical Sciences, Fudan University, Shanghai, China \\ 2 Department of General Surgery, Huashan Hospital, Fudan University; Cancer Metastasis Institute, Fudan University, \\ Shanghai, China \\ Correspondence to: Lunxiu Qin, email: qinlunxiu@huashan.org.cn \\ Keywords: hepatocellular carcinoma, CCN family proteins, metastasis, inflammatory microenvironment \\ Received: July 26, $2015 \quad$ Accepted: October 09, $2015 \quad$ Published: October 21, 2015
}

This is an open-access article distributed under the terms of the Creative Commons Attribution License, which permits unrestricted use, distribution, and reproduction in any medium, provided the original author and source are credited.

\section{ABSTRACT}

Hepatocellular carcinoma (HCC) results from an underlying chronic liver inflammatory disease, such as chronic hepatitis B or $\mathrm{C}$ virus infections, and the general prognosis of patients with HCC still remains extremely dismal because of the high frequency of HCC metastases. Throughout the process of tumor metastasis, tumor cells constantly communicate with the surrounding microenvironment and improve their malignant phenotype. Therefore, there is a strong rationale for targeting the tumor microenvironment as primary treatment of HCC therapies. Recently, CCN family proteins have emerged as localized multitasking signal integrators in the inflammatory microenvironment. In this review, we summarize the current knowledge of CCN family proteins in inflammation and the tumor. We also propose that the CCN family proteins may play a central role in signaling the tumor microenvironment and regulating the metastasis of HCC.

\section{INTRODUCTION}

Liver cancer (mainly hepatocellular carcinoma $[\mathrm{HCC}])$ is a global health problem. In men, HCC is the fifth most frequently diagnosed cancer and the second most frequent cause of cancer death, with more than $80 \%$ of HCCs occurring in developing countries [1]. Approximately three-quarters of HCCs are caused by chronic hepatitis $\mathrm{B}$ virus (HBV) and hepatitis $\mathrm{C}$ virus (HCV) infections [2]. The natural survival time of patients with advanced HCC is only approximately 3 months. Even though many advanced strategy are used in patients with HCC (i.e., early detection, surgical resection, radiofrequency, and liver transplantation), the general prognosis of patients with HCC still remains extremely dismal, and this unfavorable outcome is attributed to the high frequency of HCC metastasis [3].

A growing body of evidence suggests that metastasis is an important event in the progression of many carcinomas and is responsible for as much as $90 \%$ of cancer-associated mortalities; however, it remains the most poorly understood component of cancer pathogenesis [4]. The process of metastasis is often viewed as a complex developmental process that can be simplified into two major phases. (1) Early cancerous cells are confined to the primary tumor microenvironment by the continued expression of adhesion molecules and the intact basal lamina. As the cancer progresses, some cells in the primary tumor microenvironment start the process of morphogenesis, termed EMT (Epithelial to Mesenchymal Transition). During the EMT process, the cells acquire mesenchymal cell properties, which facilitate local invasion and metastatic dissemination [5]. (2) While the tumor cells migrate to new target organs, they change back to epithelial cell phenotype in certain premetastastatic niche, termed MET (Mesenchymal to Epithelial Transition), and develop into a metastatic lesion at that distant site [6]. Phenotypic alterations are considered a hallmark for the progression of cancer and provide a new basis for understanding how malignancies develop.

In addition to the common intrinsic heterogeneity of cancer cells that results from genomic instability, a number of phenotypic alterations are induced by the tumor's inflammatory microenvironment $[7,8]$. While converting to and from the EMT and MET states in the process of 
tumor metastasis, tumor cells constantly communicate with the surrounding microenvironment. Therefore, the development of HCC is considered to be the result of different environmental risk factors, each involving different genetic, epigenetic, and chromosomal alterations [9]. The inflammatory condition is now recognized as a hallmark feature of tumor development and metastasis [10]. In contrast to the majority of cancer types that have a relatively simple tumor microenvironment (e.g., breast, lung, and melanoma), HCC is an extraordinarily unique type of cancer in which the inflammatory conditions are present before malignant changes occur. HCC commonly develops after chronic inflammation caused by a HCV infection, HBV infection, certain metabolic liver diseases, or alcoholic injury, all of which create a tumor-permissive milieu. The tumor microenvironment of HCC is not only composed of cells typically seen in other cancers (i.e., tumor cells, fibroblasts, invading inflammatory/ immune cells, reactive oxygen and nitrogen species, tumor-associated cytokines, and chemokines). The microenvironment of $\mathrm{HCC}$ is also composed of hepatitis virus-associated inflammatory cytokines, chemokines, and growth factors, all of which create a dynamic microenvironment that contributes to the development of HCC [11]. Therefore, the liver tumor microenvironment is much more complex than that of any other cancer. The bidirectional cross talk between the tumor cells and the tumor microenvironment plays a fundamental role in the progression of the tumor and, concomitantly, the survival of patients $[12,13,14]$.
The goal of this review is to highlight the role of the microenvironment's inflammatory immune responses in $\mathrm{HCC}$ metastases and to point out the prospective areas for future research and possible precision medicine approaches to control HCC metastasis. Recently, most studies have established that $\mathrm{CCN}$ family proteins are localized multitasking signal integrators in the inflammatory microenvironment [15]. In this review, we summarize the findings on $\mathrm{CCN}$ family proteins in inflammation and in the tumor. We also propose that the CCN family proteins play a central role in regulating the tumor microenvironment and metastasis of HCC.

\section{CCN FAMILY PROTEINS}

The CCN family, first described by P. Bork in 1993, is a small, six-member family of cysteine-rich regulatory proteins found in humans. The first three members described: CCN1 (Cysteine rich 61, CYR61), CCN2 (Connective Tissue Growth Factor, CTGF), CCN3 (Nephroblastoma Overexpressed, NOV), provided the acronym for the CCN family. CCN4 (Wnt1-Inducible Signaling Pathway Proteins, WISP-1), CCN5 (WISP2), and CCN6 (WISP-3) were subsequently identified [16]. Together, the six members form the small group of structurally similar matrix proteins of approximately $40 \mathrm{kDa}$ that regulate numerous biological phenomena $[17 ; 18]$. Members of this secreted protein family share a multimodular structure with an $\mathrm{N}$-terminal secretory signal domain followed by four conserved domains with

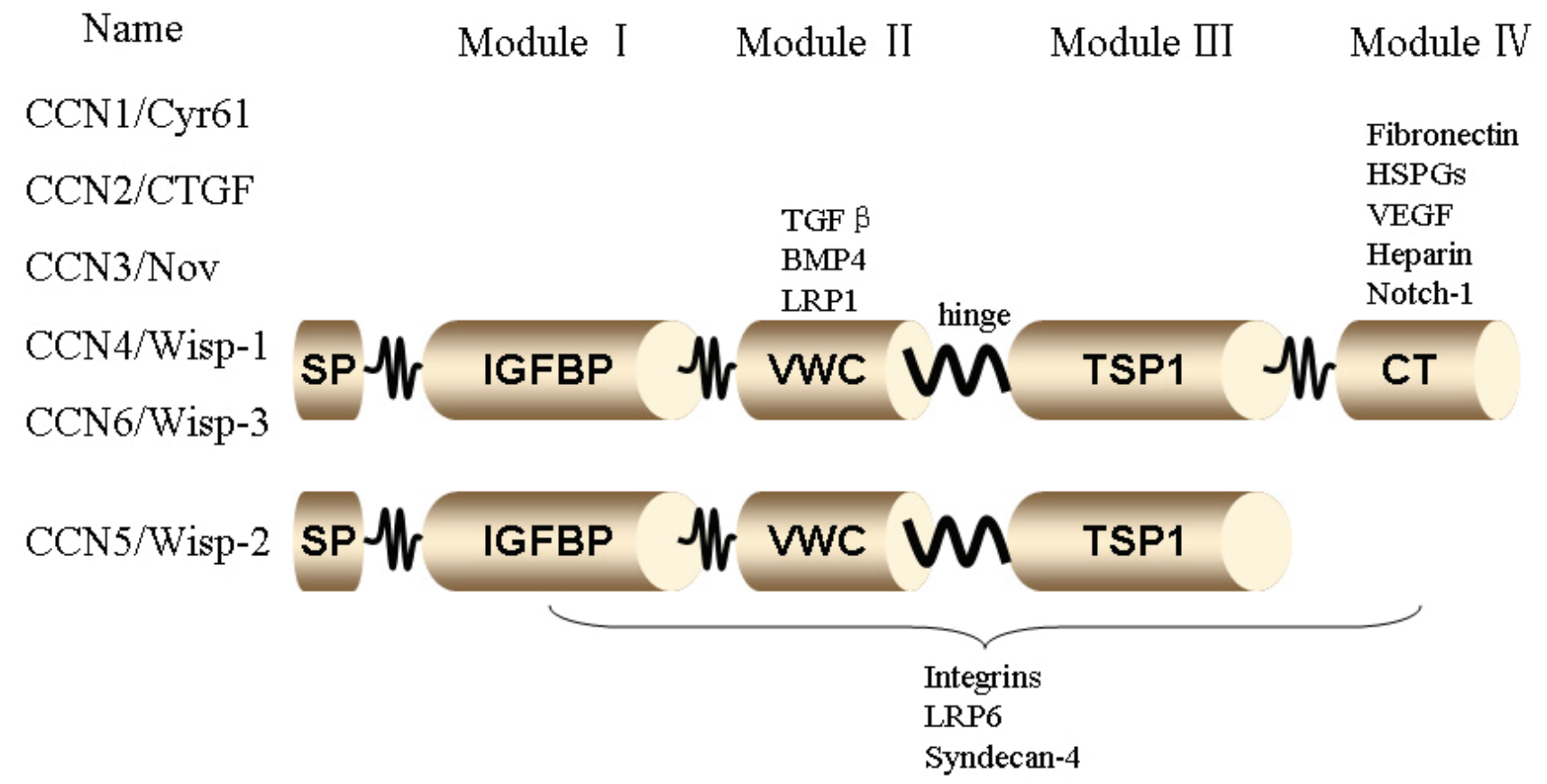

Figure 1: Structure of CCN family members. The CCN family members, CCN1 (Cyr61), CCN2 (CTGF), CCN3 (NOV), CCN4 (WISP-1), CCN5 (WISP-2), and CCN6 (WISP-3) have a shared structure, consisting of a secretory signal peptide (SP), an IGF binding domain (IGFBP), a von Willebrand type C domain (VWC), a thrombospondin-1 domain (TSP1), and a cystine knot domain (CT). The domains are linked by hinge regions and are susceptible to protease cleavage. 
Table 1: Expression of CCN family members in hepatocellular carcinoma

\begin{tabular}{ccccc}
\hline CCN Protein & Model & Effect & Ref. \\
\hline CCN1/Cyr61 & Clinical sample & Negatively correlated with HCC development & {$[34,39,115,116]$} \\
& & Positively correlated with HCC development & [35,40] \\
CCN2/CTGF & Clinical sample & Positively correlated with HCC development & {$[37,38,41,44]$} \\
CCN3/NOV & Clinical sample & Positively correlated with HCC development & {$[34,37]$} \\
CCN4/WISP-1 & Clinical sample & Negatively correlated with HCC development & [34] \\
CCN5/WISP-2 & Clinical sample & & No significant difference & [34] \\
CCN6/WISP-3 & - & Lack of data & - \\
\hline
\end{tabular}

homologies to Module I (insulin-like growth factor binding proteins, IGFBP), Module II (von Willebrand factor type C repeat, VWC), Module III (thrombospondin type I repeat, TSP), and Module IV (carboxy-terminal domain, CT) containing a cystine knot [19] (Figure 1). Because the $\mathrm{CCN}$ proteins are characterized by four unique globular modules that share homology with functional domains of various extracellular proteins, this family does not behave like traditional growth factors or cytokines. The proteins do not appear to have a unique receptor for high-affinity binding and signal transduction. In recent years, there has been much interest in this family of proteins, mainly to understand the function of their multimodular structures [20].

It may be more accurate to think of $\mathrm{CCN}$ family proteins as matricellular proteins that modulate cellmatrix interaction to modify the cellular phenotype [21]. $\mathrm{CCN}$ family proteins are not ubiquitously or constitutively expressed, but are under strict regulation by a number of extracellular stimuli. Many studies have shown how physiological and pathological events acting on each catalytic domain of CCNs affect differentiation [22], adhesion [23, 24], migration [25, 26], mitogenesis [27], chemotaxis [28] and angiogenesis [29]. Furthermore, CCN proteins participate in the development of cartilage and bone, the nervous system, and hematopoietic stem cells $[30,31,32]$. Many of the above-mentioned phenomena are also associated with cancer [33], implying that these proteins may also have a role in malignancy. Chronic liver damage is a paradigm of cancer-related inflammation caused by hepatitis virus infection, alcoholic injury, etc. Chemokines, cytokines, growth factors, and inflammatory mediators regulate the infrastructure of the tumor inflammatory microenvironment by deciding the signal transduction and functional outcome of tumor cells. This review summarizes the relevant literature on $\mathrm{CCNs}$ as core regulatory proteins that orchestrate the inflammatory microenvironment.

\section{CCN FAMILY PROTEINS IN HCC}

\section{Altered expression of $\mathrm{CCN}$ proteins in $\mathrm{HCC}$}

In $\mathrm{HCC}$, the expression levels of CCN1, CCN2, $\mathrm{CCN} 3$, and $\mathrm{CCN} 4$ are closely correlated with certain biological characteristics and clinical features, including venous invasion, cellular differentiation, TNM stage, disease-free survival, and overall survival. All of these features are valuable in determining prognosis [34, $35,36,37,38]$. Chen et al [39] showed that CCN1 expression was downregulated in human $\mathrm{HCC}$, and CCN1 suppressed hepatocarcinogenesis by inhibiting EGFR-dependent hepatocyte compensatory proliferation. Paradoxically, Zeng et al [35] reported CCN1 mRNA in carcinoma tissues were significantly higher than those in para-cancerous normal liver tissues, which play an important role in hepatocellular carcinogenesis and correlate with recurrence and metastasis of HCC. Li et al [40] also found that $\mathrm{CCN} 1$ was a direct downstream target of $\mathrm{Wnt} / \beta$-catenin signaling, activation of $\beta$-catenin signaling elevated the level of CCN1 in HCC cells, which promoted the progression of HCC. It was proved expression of $\mathrm{CCN} 2$ was an independent factor associated with shorter OS in HCC [34, 41, 42]. Hou et al [43] proved CCN2 were related to the formation of HCC BM (Bone Metastases), which could serve as a potential prognostic biomarkers for BM from HCC [44]. While, the inhibition of $\mathrm{CCN} 2$ expression can block the progression of HCC [45]. Enhanced expression of CCN3 were found in HCC samples when compared to levels in matched non-cancerous tissues, and these results suggest that Nov was associated with the development of tumors in the live $[34,37]$. CCN4 was also proved as a negative correlation with OS in HCC [34], contributing to the Wnt pathway activation [46]. No significant difference in CCN5 was found between HCC samples and matchedpair normal liver samples [34]. Although, it was reported overexpression of the hepatitis $\mathrm{C}$ viral core protein in Huh7 cells caused an upregulation of CCN5 and increased proliferation of the cells [47], it was still hard to tell the role of CCN5 in HCC malignant phenotype. Report of 
CCN6 expression in HCC is still lacking. Our colleagues Ye et al [48] analyzed the cDNA microarray-based gene expression profile of HCC samples with or without extra-hepatic metastases. They found that CCN3 was significantly upregulated in metastatic HCC. Recently, we confirmed that high expression levels of CCN2 and CCN3 were correlated with poor prognosis in $\mathrm{HCC}$ patients using tissue microarray (unpublished data). We also analyzed the profiles of tissue from patients with oxaliplatin-resistant $\mathrm{HCC}$ and found significantly upregulated expression of CCN1 and CCN3 [49]. The expression of CCN family proteins in HCC clinical sample was summarized in Table1.

\section{Altered expression of $\mathrm{CCN}$ proteins in $\mathrm{HCC}$ stroma}

$\mathrm{CCN}$ family proteins paracrined by $\mathrm{HCC}$ stromal cells are also closely correlated with HCC progression. Our group has collaborated with the United States' National Cancer Institute to compare the gene expression profiles of noncancerous surrounding hepatic tissue from primary HCC with or without metastases. This study found a unique change in the gene expression profile in the noncancerous hepatic tissues of metastatic tumors with more than $30 \%$ of them associated with inflammation and/ or immune response functions. CCN3 was significantly upregulated compared with the liver tissue of nonmetastatic HCC. CCN1, CCN2 also have corresponding upregulation, and $\mathrm{CCN} 4$ was down regulated significantly [50]. We confirmed this finding of higher expression levels of CCN2 and CCN3 in the noncancerous surrounding hepatic tissue from primary metastatic $\mathrm{HCC}$ using tissue microarrays (unpublished data). Kim [51] et al found that CCN1 is highly accumulated in the hepatocytes of human cirrhotic livers where it acts as a key regulator in the accumulation of reactive oxygen species (ROS) [52]. High levels of ROS could trigger the activation of macrophages and cause immunosuppression in the tumor microenvironment. The involvement of platelets in tumor progression has been well recognized for decades. CCN1 is released from or produced by activated platelets at levels more than 20-fold higher than any other growth factors [53], suggesting that platelets constitute a novel source of CCN1 release and may play central roles in tumor progression [54]. Higher serum CCN2 concentrations in patients with $\mathrm{HCC}$ are most likely due to the active fibrogenic tissue matrix surrounding the tumor [55] and played an important role in the progression of HCC and relationship with angiogenesis of HCC [56]. They also found that $\mathrm{CCN} 2$ silencing induced a sustained antifibrotic effect in a mouse model [57].

$\mathrm{CCN}$ proteins are inducible immediate early genes involved in diverse physiological and pathological processes after exposure to various stimuli. In unpublished data from our lab, we found higher expression of CCN proteins in the parenchyma and stroma of HCC tumors with extra-hepatic metastases. Taken together, this suggests that the malignant potential of HCC may be determined not only by the intrinsic heterogeneity resulting from genomic instability, but also may be determined by the tumor microenvironment, which is influenced by $\mathrm{CCN}$ proteins.

\section{THE RELATIONSHIP BETWEEN INFLAMMATION MICROENVIRONMENT AND CCN PROTEINS}

One hypothesis views tumors as non-healing wounds with a close link to the chronic inflammatory microenvironment. Supporting this idea, HCC typically occurs in an inflammatory fibrotic microenvironment in the liver, caused by chronic liver damage [58]. Global gene expression profiling has revealed that the tumor microenvironment is important in the biologic and prognostic classification of the tumor [50]. Inflammation is a complex process regulated by an extraordinarily large variety of immune cells and a cascade of cytokines and chemokines synthesized in the inflammatory region. This is especially true in HCC. Divella [59] et al demonstrated that tumor heterogeneity is closely linked with inflammation in the presence of $\mathrm{HBV} / \mathrm{HCV}$ and confirmed that the presence of viral infections increases the risk for HCC development. Shin [60] et al found that $\mathrm{HCV}$ core proteins could promote hepatic fibrogenesis via upregulation of CCN2. Samuel [61] et al found that hepatitis $\mathrm{B}$ viral protein ( $\mathrm{HBx}$ )-expressing hepatocytes showed an increased expression of CCN2, which is a major cause of liver fibrosis that eventually leads to cirrhosis and HCC. Bian et al [62] found that CCN1 expression in hepatocytes is involved in the hepatic proinflammatory response and macrophage infiltration.

The multimodular structure of the $\mathrm{CCN}$ proteins allows them to bind and interact with a broad range of other extracellular proteins, including integrins, heparin sulfate proteoglycans (HSPGs), extracellular matrix proteins (e.g., fibronectin and fibulin 1C), receptors (e.g., Notch1 and tropomyosin receptor kinase A [TrkA]), lowdensity lipoprotein receptor-related proteins (LRPs), and cytokines (e.g., bone morphogenetic proteins, transforming growth factor- $\beta$ [TGF- $\beta$ ], connexin 43, and vascular endothelial growth factor). This flexibility enables $\mathrm{CCN}$ proteins to play a core role in inflammatory cytokine synthesis and immune cell recruitment during the inflammatory process [63]. (Figure 1) 


\section{Cytokine and chemokine secretion induced by CCN proteins}

There is growing evidence that the expression of $\mathrm{CCN}$ proteins is regulated by cytokines $[64,65$, 66, 67, 68, 69]. Reciprocally, CCN proteins could differentially modulate the secretion of cytokines through a variety of signaling pathways. For example, $\mathrm{CCN} 1 \mathrm{can}$ activate integrin-nuclear factor $\kappa \mathrm{B}(\mathrm{NF \kappa B})$ signaling in macrophages, leading to the expression of multiple proinflammatory signals, including upregulation of cytokines (tumor necrosis factor $\alpha[\mathrm{TNF} \alpha]$, interleukin [IL]-1 $\alpha$, IL-1 $\beta$, IL-6, IL-12b), chemokines (MIP-1 $\alpha$, MCP-3, Gro1, Gro2, IP-10), regulators of oxidative stress, and the complement system (inducible nitric oxide synthase, C3) [70, 71]. In gastric cancer cells, CCN1 can upregulate $\mathrm{COX}-2$ and the chemokine receptors $\mathrm{CXCR} 1$ and $\mathrm{CXCR} 2$ via NF- $\mathrm{KB}$ and Scr/PI3K/Akt-dependent pathways, respectively $[72,73]$. In other cell systems (for example, stellate cells, cardiomyocytes, and mesangial cells), $\mathrm{CCN} 2$ can regulate the proinflammatory cytokines TNF $\alpha$ and IL- 6 and the chemokines MCP1 and IL- 8 through NF- $\mathrm{\kappa B}$ signaling during inflammation $[74,75$, $76,77]$. CCN3 specifically induces the expression of the proinflammatory chemokines MCP1 and GRO $\alpha$ in primary cultured astrocytes through distinct integrins and signaling mechanisms, such as activation of integrin $\beta 1 /$ Rho/ROCK/JNK/NF- $\kappa B$ and integrin $\beta 5 /$ Rho/ROCK/ p38/NF- $\mathrm{BB}$ pathways, respectively [78]. In cancer cells and vascular smooth muscle cells, overexpression of CCN4 and CCN5 leads to downregulation of matrix metalloproteinase (MMP)-1 and MMP-2, respectively $[79,80]$. There is clear evidence that $\mathrm{CCN}$ family proteins can activate proinflammatory pathways, making them a potentially important signal in cancer cells.

\section{Cytokine and chemokine activity orchestrated by CCN proteins}

According to the published literature, $\mathrm{CCN}$ proteins display proinflammatory and anti-inflammatory activities in a cell type-specific manner, indicating that this family of proteins could be a core modulator of the inflammatory microenvironment. CCN1, CCN2, and $\mathrm{CCN} 3$ are able to unmask the cytotoxicity of TNF $\alpha$ and lymphotoxin- $\alpha$, as well as enhance the apoptotic activity of the Fas ligand (FasL) and the TNF-related apoptosis-inducing ligand (TRAIL) in normal human skin fibroblasts [81]. Paradoxically, CCN1 contributes to prostate cancer cell proliferation and TRAIL-induced apoptosis, the latter effect through interaction with integrins av $\beta 3$ and a6 $\beta 4$, syndecan-4, and PKC $\alpha$-dependent signaling [82]. CCN2 can modulate the bioavailability and/or activity of TGF- $\beta$ through its VWC domain and thereby potentiate TGF- $\beta$ receptor binding and signaling [83, 84]. In cultured astrocytes, $\mathrm{CCN} 3$ added in combination with $\mathrm{TNF} \alpha$ synergizes the stimulatory effect of TNF $\alpha$ on GRO $\alpha$ expression [63]. CCN4 exerts pro-mitogenic and prosurvival effects, partly by antagonizing TNF $\alpha$-mediated cardiomyocyte death [85].

\section{Immune cells orchestrated by $\mathrm{CCN}$ proteins}

The most ubiquitous function of the $\mathrm{CCN}$ proteins is their ability to support adhesion and regulate migration, proliferation, survival, and apoptosis. All of these factors contribute to the recruitment of immune cells or angiogenesis, which are crucial processes that involve the inflammatory microenvironment. Leukocyte transmigration is a multi-step event that is considered a hallmark of inflammation. CCN1 can induce cell adhesion and thereby contribute to the recruitment of leukocytes and macrophages to the inflammatory sites in an integrindependent manner [86]. In vivo, CCN2 also markedly promotes infiltration of $\mathrm{T}$ lymphocytes, monocytes, and macrophages into the renal interstitium [74]. Chen [24] et al has shown that prostate cancer-derived $\mathrm{CCN} 3$ can induce M2 macrophage infiltration, increase tumor growth, and support tumor-associated angiogenesis in the tumor microenvironment. $\mathrm{CCN} 1$ can promote the integrin-dependent recruitment of $\mathrm{CD} 4^{+}$progenitor cells to endothelial cells, thereby enhancing endothelial proliferation and neovascularization in vitro and in vivo [87]. CCN4 [88], CCN5 [80], and CCN6 [89] seem to play a preventive role in tumor progression. Antonio et al [90] found that inhibiting CCN2 expression can interrupt the cross talk between $\mathrm{HCC}$ and fibroblasts, leading to a significant reduction of HCC growth and dissemination. (Figure 2)

\section{ROLE OF INFLAMMATORY MICROENVIRONMENT IN THE MALIGNANT PHENOTYPE OF HCC}

Uncontrolled or sustained inflammation is the underlying cause of or actively contributes to the progression of tumor [91, 92, 93, 94]. The liver tumor inflammatory microenvironment is a complex mixture of HCC cells within the ECM, combined with a complex mix of stromal cells and the proteins they secrete. Together, these elements contribute to the HCC epigenetic alterations. Cancer cells do not manifest the disease alone and the stroma is inappropriately activated in cancer to contribute to malignant characteristics of tumor cells. The stroma and the tumor cells create a complex system with reciprocal signaling [95]. The condition of HCC inflammatory microenvironment is now recognized as a hallmark feature of tumor development and metastasis [8]. The functions of CCN proteins are involved in the regulations of inflammatory microenvironment $[15$, 
96, 97]. In particular, CCNs expression is regulated by cytokines and immune cells, and that, reciprocally, CCNs may regulate cytokines, chemokines expression and immune cell functions. So, $\mathrm{CCN}$ proteins can represent a new class of mediators that contribute to the fine tuning of HCC's inflammatory regulations [45, 98, 99].

\section{NEW APPROACHES TO TARGET CCN PROTEINS IN HCC}

Technological advancements in the molecular characterization of cancers have enabled researchers to identify an increasing number of key molecular drivers of cancer progression [100,101, 102, 103]. There have been several examples of successful monoclonal antibody and small molecule drug, particularly those targeting key molecular pathways in the field of oncology over the past decade $[104 ; 105 ; 106]$. To date, Sunitinib, Brivanib, Linifanib, Sorafenib and other molecules tested as secondline therapies for advanced HCC, failed to demonstrate an increased survival compared to placebo [107]. What are the possible reasons for the failure? As our understanding of the complex interplay between tumor and stroma, different components of the tumor's inflammatory microenvironment play a significant role in each step of cancer progression, such as angiogenesis, invasion, and metastasis [108]. HCC emerges late in the course of the $\mathrm{HBV}$ or HCV infection, after years of inflammation and constant regeneration have led to substantial fibrosis and a constellation of molecular changes that culminate in cancer. The prevailing hypothesis is that HCC is nearly always the result of inflammation; therefore, future therapeutic strategies should focus on targeting this inflammation.

Abnormal levels of CCN proteins have been widely reported in human cancers and stromal cells in the tumor microenvironment where they can either enhance or inhibit cancer cell growth [109]. CCN proteins, along with other proteins such as thrombospondins and osteopontins, are matricellular proteins that modify the signaling pathways of other molecules, especially those associated with inflammation. Because $\mathrm{CCN}$ proteins influence multiple physiological and pathological processes, therapy targeted to this protein family has many potential clinical applications for cancer, especially HCC.

FG-3019 is a monoclonal antibody against CCN2 that was tested in locally advanced or metastatic pancreatic cancer in a phase I study. The experimental drug was administered combination with Erlotinib and

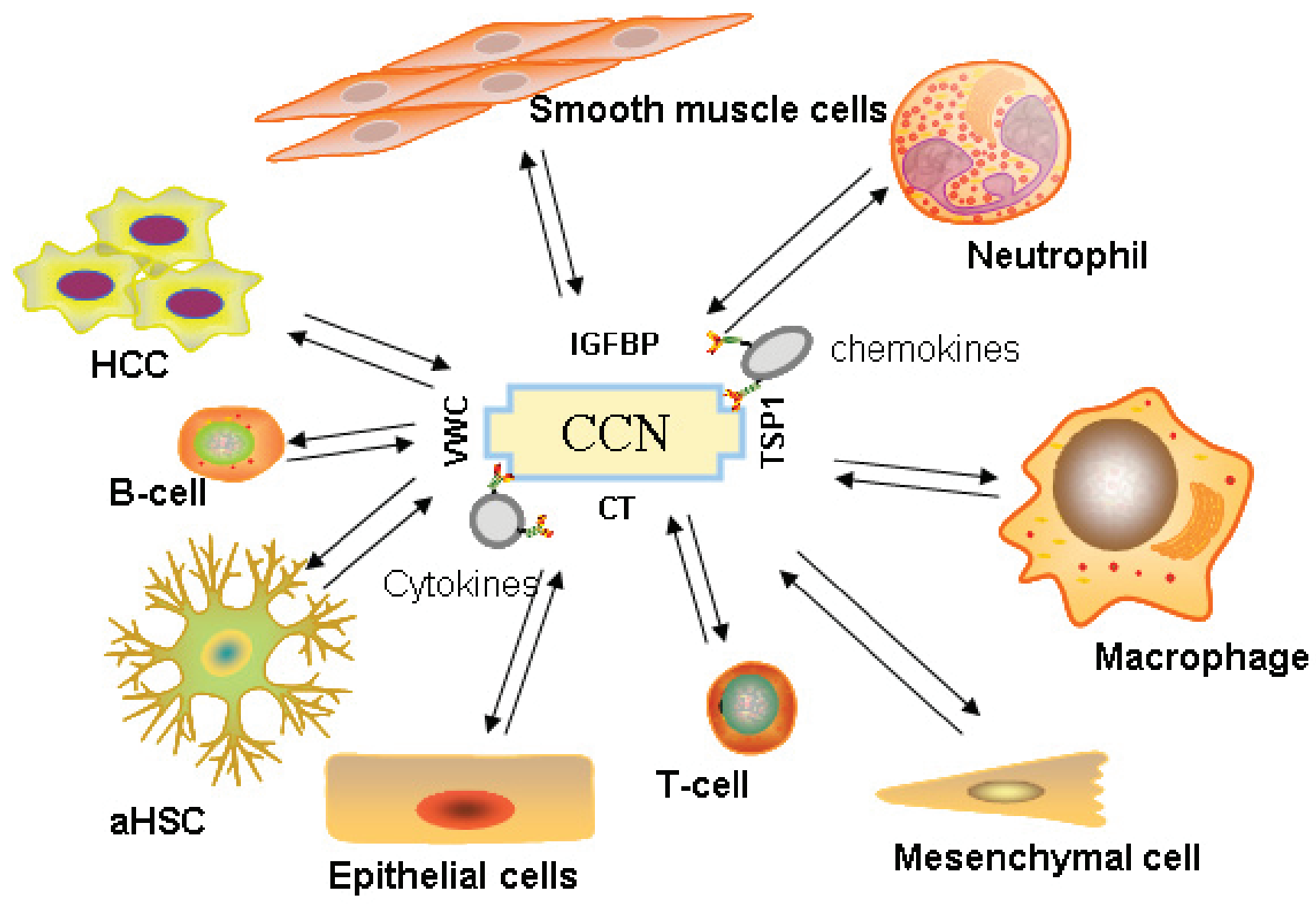

Figure 2: Immune signaling orchestrated by $\mathbf{C C N}$ proteins. Cytokines, chemokines, stromal cells, and other immune cells in the HCC tumor's inflammatory microenvironment are influenced by CCN proteins. 
Gemcitabine; no toxicity was found relating to FG-3019. Patients progressed after a median time of 3.7 months and had a median survival of 9.4 months [110]. FG-3019 has been tested previously in a phase I study in patients with microalbuminuric diabetic kidney disease. Here, the researchers demonstrated a saturable pathway for drug elimination, minimal infusion adverse events, and no significant drug-attributable adverse effects over the year of follow-up [111]. Neesse [112] et al found that tumor-stromal interactions critically contribute to innate drug resistance in pancreatic cancer and that targeting tumor microenvironmental factors through CCN2 played an important role in treatment responses. Finger [113] et al offered the first preclinical validation of anti-CCN2 therapy for the treatment of advanced melanoma. Because of its reasonable toxicity spectrum, FG3091 is ready to be tested in phase II trials in patients with pancreatic cancer [114]. These preclinical studies provide strong evidence for targeting $\mathrm{CCN}$ proteins in HCC therapy. Inhibition of $\mathrm{CCN}$ proteins, especially $\mathrm{CCN} 2$, represents a new therapeutic strategy that may be used alone or in combination with current treatments for HCC.

\section{SUMMARY AND PROSPECTS}

HCC is nearly always the result of underlying chronic liver inflammation, usually viral hepatitis. The choice and outcome of treatment depend on the extent of the tumor and the overall condition of the liver. Currently, drug development in HCC remains focusing on HCC itself, which could be ignorance of the importance of the HCC microenvironment driving a tumor-permissive milieu. Throughout the process of tumor metastasis, tumor cells constantly communicate with the surrounding microenvironment and improve their malignant potential. Now that the inflammatory condition is recognized as a hallmark feature of tumor development and metastasis, better therapies will hopefully follow.

CCN family proteins have emerged as localized multitasking signal integrators in the inflammatory microenvironment. $\mathrm{CCN}$ proteins are modular proteins containing as many as four distinct functional domains involved in binding to cytokines, chemokines, and cell surfaces molecules, including integrins, HSPGs, and LRPs et al, which play important roles in tumorigenesis, proliferation, adhesion, migration, and survival. Although most CCN family members were discovered more than a decade ago, the precise physiological function and mechanism of action of these proteins remain elusive, especially for the tumor microenvironment. Future directions should be focused on how the inflammatory microenvironment regulates tumor progression, especially in HCC. A thorough understanding of the biological functions of $\mathrm{CCN}$ proteins would provide insights into their roles in numerous cellular processes and offer opportunities to develop potential therapeutics.

\section{Abbreviations}

HCC, hepatocellular carcinoma; HBV, hepatitis $\mathrm{B}$ virus; $\mathrm{HCV}$ hepatitis $\mathrm{C}$ virus; EMT, epithelial to mesenchymal transition; CYR61, cysteine rich 61; CTGF, connective tissue growth factor; NOV, nephroblastoma overexpressed; WISP-1, wnt1-inducible signaling pathway proteins; WISP-2, wnt2-inducible signaling pathway proteins; WISP-3, wnt1-inducible signaling pathway proteins; IGFBP, insulin-like growth factor binding proteins; VWC, von willebrand factor type $\mathrm{C}$ repeat; TSP, thrombospondin type I repeat; CT, carboxy-terminal domain; ROS, reactive oxygen species; HBx, hepatitis B viral protein; HSPGs, heparin sulfate proteoglycans

\section{ACKNOWLEDGMENTS}

This research project was supported by China National Key Projects for Infectious Disease (2012ZX10002-012), the National Key Basic Research Program of China (2014CB542101, 2013CB910500), the National Natural Science Foundation of China (81502694), and Postdoctoral Science Foundation of China (2015M570330).

\section{CONFLICTS OF INTEREST}

The authors declare that they have no competing interests

\section{Authors' contributions}

Qingan Jia drafted the manuscript. Qiongzhu Dong gave helpful discussions and did the critical reading of the manuscript. Lunxiu Qin carried out the finial revision and provided important suggestions.

\section{REFERENCES}

1. Jemal A, Bray F, Center MM, Ferlay J, Ward E and Forman D. Global Cancer Statistics. Ca-a Cancer Journal for Clinicians. 2011; 61:69-90.

2. Yang JD and Roberts LR. Hepatocellular carcinoma: a global view. Nature Reviews Gastroenterology \& Hepatology. 2010; 7:448-458.

3. Page AJ, Cosgrove DC, Philosophe B and Pawlik TM. Hepatocellular Carcinoma Diagnosis, Management, and Prognosis. Surgical Oncology Clinics of North America. 2014; 23:289-311.

4. Chaffer CL and Weinberg RA. A Perspective on Cancer Cell Metastasis. Science. 2011; 331:1559-1564.

5. Jung HY, Fattet L and Yang J. Molecular pathways: linking tumor microenvironment to epithelial-mesenchymal transition in metastasis. Clin Cancer Res. 2015; 21:962-968. 
6. Guo F, Parker Kerrigan BC, Yang D, Hu L, Shmulevich I, Sood AK, Xue F and Zhang W. Post-transcriptional regulatory network of epithelial-to-mesenchymal and mesenchymal-to-epithelial transitions. J Hematol Oncol. 2014; 7:19.

7. Sun Z, Wang S and Zhao RC. The roles of mesenchymal stem cells in tumor inflammatory microenvironment. J Hematol Oncol. 2014; 7:14.

8. Hernandez-Gea V, Toffanin S, Friedman SL and Llovet JM. Role of the microenvironment in the pathogenesis and treatment of hepatocellular carcinoma. Gastroenterology. 2013; 144:512-527.

9. Mantovani A, Allavena P, Sica A and Balkwill F. Cancerrelated inflammation. Nature. 2008; 454:436-444.

10. Diakos CI, Charles KA, McMillan DC and Clarke SJ. Cancer-related inflammation and treatment effectiveness. Lancet Oncol. 2014; 15:e493-503.

11. Farazi PA and DePinho RA. Hepatocellular carcinoma pathogenesis: from genes to environment. Nature Reviews Cancer. 2006; 6:674-687.

12. Balkwill F, Charles KA and Mantovani A. Smoldering and polarized inflammation in the initiation and promotion of malignant disease. Cancer Cell. 2005; 7:211-217.

13. Yu H, Kortylewski M and Pardoll D. Crosstalk between cancer and immune cells: role of STAT3 in the tumour microenvironment. Nature Reviews Immunology. 2007; 7:41-51.

14. Heindryckx F and Gerwins P. Targeting the tumor stroma in hepatocellular carcinoma. World J Hepatol. 2015; 7:165176.

15. Kular L, Pakradouni J, Kitabgi P, Laurent M and Martinerie C. The CCN family: A new class of inflammation modulators? Biochimie. 2011; 93:377-388.

16. Zuo GW, Kohls CD, He BC, Chen L, Zhang WL, Shi Q, Zhang BQ, Kang Q, Luo JY, Luo XJ, Wagner ER, Kim SH, Restegar F, Haydon RC, Deng ZL, Luu HH, et al. The CCN proteins: important signaling mediators in stem cell differentiation and tumorigenesis. Histology and Histopathology. 2010; 25:795-806.

17. Katsube K, Sakamoto K, Tamamura Y and Yamaguchi A. Role of $\mathrm{CCN}$, a vertebrate specific gene family, in development. Development Growth \& Differentiation. 2009; 51:55-67.

18. Holbourn KP, Acharya KR and Perbal B. The CCN family of proteins: structure-function relationships. Trends Biochem Sci. 2008; 33:461-473.

19. Brigstock DR, Goldschmeding R, Katsube K, Lam SCT, Lau LF, Lyons K, Naus C, Perbal B, Riser B, Takigawa M and Yeger H. Proposal for a unified CCN nomenclature. Molecular Pathology. 2003; 56:127-128.

20. Kubota $\mathrm{S}$ and Takigawa M. Cellular and molecular actions of CCN2/CTGF and its role under physiological and pathological conditions. Clinical Science. 2015; 128:181196.
21. Jun JI and Lau LF. Taking aim at the extracellular matrix: $\mathrm{CCN}$ proteins as emerging therapeutic targets. Nature Reviews Drug Discovery. 2011; 10:945-963.

22. Nishida T, Kubota S, Aoyama E, Janune D, Lyons KM and Takigawa M. CCN family protein 2 (CCN2) promotes the early differentiation, but inhibits the terminal differentiation of skeletal myoblasts. J Biochem. 2015 ;157:91-100.

23. Chen YL, Abraham DJ, Xu SW, Pearson JD, Black CM, Lyons KM and Leask A. CCN2 (connective tissue growth factor) promotes fibroblast adhesion to fibronectin. Molecular Biology of the Cell. 2004; 15:5635-5646.

24. Chen PC, Cheng HC, Wang J, Wang SW, Tai HC, Lin CW and Tang $\mathrm{CH}$. Prostate cancer-derived CCN3 induces M2 macrophage infiltration and contributes to angiogenesis in prostate cancer microenvironment. Oncotarget. 2014; 5:1595-1608. Doi: 10.18632/oncotarget. 1570.

25. Chen PS, Wang MY, Wu SN, Su JL, Hong CC, Chuang SE, Chen MW, Hua KT, Wu YL, Cha ST, Babu MS, Chen $\mathrm{CN}$, Lee PH, Chang KJ and Kuo ML. CTGF enhances the motility of breast cancer cells via an integrin-alpha $\mathrm{v}$ beta 3-ERK1/2-dependent S100A4-upregulated pathway. Journal of Cell Science. 2007; 120:2053-2065.

26. Cui L, Xie R, Dang S, Zhang Q, Mao S, Chen J, Qu J and Zhang J. NOV promoted the growth and migration of pancreatic cancer cells. Tumour Biol. 2014; 35:3195-3201.

27. Weiskirchen R. CCN proteins in normal and injured liver. Front Biosci (Landmark Ed). 2011; 16:1939-1961.

28. Ouellet V, Tiedemann K, Mourskaia A, Fong JE, TranThanh D, Amir E, Clemons M, Perbal B, Komarova SV and Siegel PM. CCN3 Impairs Osteoblast and Stimulates Osteoclast Differentiation to Favor Breast Cancer Metastasis to Bone. American Journal of Pathology. 2011; 178:2377-2388.

29. Chuang JY, Chen PC, Tsao CW, Chang AC, Lein MY, Lin CC, Wang SW, Lin CW and Tang CH. WISP-1 a novel angiogenic regulator of the $\mathrm{CCN}$ family promotes oral squamous cell carcinoma angiogenesis through VEGF-A expression. Oncotarget. 2015; 6(6):4239-4252. Doi: 10.18632/oncotarget.2978.

30. Su BY, Cai WQ, Zhang CG, Martinez V, Lombet A and Perbal B. The expression of cen3 (nov)* RNA and protein in the rat central nervous system is developmentally regulated. Molecular Pathology. 2001; 54:184-191.

31. Takigawa M. CCN2: a master regulator of the genesis of bone and cartilage. J Cell Commun Signal. 2013; 7:191201.

32. Gupta R, Hong DL, Iborra F, Sarno S and Enver T. NOV (CCN3) functions as a regulator of human hematopoietic stem or progenitor cells. Science. 2007; 316:590-593.

33. Tsai HC, Huang CY, Su HL and Tang CH. CCN2 enhances resistance to cisplatin-mediating cell apoptosis in human osteosarcoma. PLoS One. 2014; 9:e90159.

34. Zhang H, Li W, Huang P, Lin L, Ye H, Lin D, Koeffler HP, Wang $\mathrm{J}$ and Yin D. Expression of CCN family members 
correlates with the clinical features of hepatocellular carcinoma. Oncol Rep. 2015; 33:1481-1492.

35. Zeng ZJ, Yang LY, Ding X and Wang W. Expressions of cysteine-rich61, connective tissue growth factor and Nov genes in hepatocellular carcinoma and their clinical significance. World J Gastroenterol. 2004; 10:3414-3418.

36. Xiang ZL, Zeng ZC, Fan J, Tang ZY and Zeng HY. Expression of connective tissue growth factor and interleukin-11 in intratumoral tissue is associated with poor survival after curative resection of hepatocellular carcinoma. Mol Biol Rep. 2012; 39:6001-6006.

37. Hirasaki S, Koide N, Ujike K, Shinji T and Tsuji T. Expression of Nov, CYR61 and CTGF genes in human hepatocellular carcinoma. Hepatol Res. 2001; 19:294-305.

38. Xiu M, Liu YH, Brigstock DR, He FH, Zhang RJ and Gao RP. Connective tissue growth factor is overexpressed in human hepatocellular carcinoma and promotes cell invasion and growth. World Journal of Gastroenterology. 2012; 18:7070-7078.

39. Chen CC, Kim KH and Lau LF. The matricellular protein CCN1 suppresses hepatocarcinogenesis by inhibiting compensatory proliferation. Oncogene. 2015 Jun 1. doi: 10.1038/onc.2015.190.

40. Li ZQ, Ding W, Sun SJ, Li J, Pan J, Zhao C, Wu WR and Si WK. Cyr61/CCN1 is regulated by Wnt/beta-catenin signaling and plays an important role in the progression of hepatocellular carcinoma. PLoS One. 2012; 7:e35754.

41. Lamarca A, Mendiola M, Bernal E, Heredia V, Diaz E, Miguel M, Pastrian LG, Burgos E, Feliu J and Barriuso J. Tumoural expression of connective tissue growth factor (CTGF) impacts on survival in patients diagnosed with hepatocellular carcinoma (HCC). Curr Cancer Drug Targets. 2015;15:435-44.

42. Lamarca A, Mendiola M, Bernal E, Heredia V, Diaz E, Miguel M, Pastrian LG, Burgos E, Feliu J and Barriuso J. Tumoural Expression of Connective Tissue Growth Factor (CTGF) Impacts on Survival in Patients Diagnosed with Hepatocellular Carcinoma (HCC). Curr Cancer Drug Targets. 2015; 15:435-444.

43. Hou R, Wang YW, Liang HF, Zhang ZG, Liu ZM, Zhang $\mathrm{BH}$, Zhang BX and Chen XP. Animal and cellular models of hepatocellular carcinoma bone metastasis: establishment and characterisation. J Cancer Res Clin Oncol. 2015 ;141:1931-43.

44. Xiang ZL, Zeng ZC, Tang ZY, Fan J, He J, Zeng HY and Zhu XD. Potential prognostic biomarkers for bone metastasis from hepatocellular carcinoma. Oncologist. 2011; 16:1028-1039.

45. Mazzocca A, Fransvea E, Dituri F, Lupo L, Antonaci S and Giannelli G. Down-Regulation of Connective Tissue Growth Factor by Inhibition of Transforming Growth Factor beta Blocks the Tumor-Stroma Cross-Talk and Tumor Progression in Hepatocellular Carcinoma. Hepatology. 2010; 51:523-534.
46. Cervello M, Giannitrapani L, Labbozzetta M, Notarbartolo M, D'Alessandro N, Lampiasi N, Azzolina A and Montalto G. Expression of WISPs and of their novel alternative variants in human hepatocellular carcinoma cells. Ann N Y Acad Sci. 2004; 1028:432-439.

47. Fukutomi T, Zhou Y, Kawai S, Eguchi H, Wands JR and Li J. Hepatitis C virus core protein stimulates hepatocyte growth: correlation with upregulation of wnt-1 expression. Hepatology. 2005; 41:1096-1105.

48. Ye QH, Qin LX, Forgues M, He P, Kim JW, Peng AC, Simon R, Li Y, Robles AI, Chen YD, Ma ZC, Wu ZQ, Ye SL, Liu YK, Tang ZY and Wang XW. Predicting hepatitis $B$ virus-positive metastatic hepatocellular carcinomas using gene expression profiling and supervised machine learning. Nature Medicine. 2003; 9:416-423.

49. Bu Y, Jia QA, Ren ZG, Zhang JB, Jiang XM, Liang L, Xue TC, Zhang QB, Wang YH, Zhang L, Xie XY and Tang ZY. Maintenance of Stemness in Oxaliplatin-Resistant Hepatocellular Carcinoma Is Associated with Increased Autocrine of IGF1. Plos One. 2014; 9:e89686.

50. Budhu A, Forgues M, Ye QH, Jia HL, He P, Zanetti KA, Kammula US, Chen Y, Qin LX, Tang ZY and Wang XW. Prediction of venous metastases, recurrence, and prognosis in hepatocellular carcinoma based on a unique immune response signature of the liver microenvironment. Cancer Cell. 2006; 10:99-111.

51. Kim KH, Chen CC, Monzon RI and Lau LF. Matricellular Protein CCN1 Promotes Regression of Liver Fibrosis through Induction of Cellular Senescence in Hepatic Myofibroblasts. Molecular and Cellular Biology. 2013; 33:2078-2090.

52. Ghosh S, Mukherjee S, Choudhury S, Gupta P, Adhikary A, Baral R and Chattopadhyay S. Reactive oxygen species in the tumor niche triggers altered activation of macrophages and immunosuppression: Role of fluoxetine. Cell Signal. $2015 ; 27: 1398-412$.

53. Wang YH, Sun YP, Li D, Zhang L, Wang KM, Zuo Y, Gartner TK and Liu JL. Platelet P2Y12 Is Involved in Murine Pulmonary Metastasis. Plos One. 2013; 8.

54. Cetinkunar S, Guzel H, Emre Gokce I, Erdem H, Gulkan S, Aktimur R, Kucuk B, Imamoglu I and Kargici H. High levels of platelet/lymphocyte ratio are associated with metastatic gastric cancer. J BUON. 2015; 20:78-83.

55. Gressner OA, Fang M, Li H, Lu LG, Gressner AM and Gao CF. Connective tissue growth factor (CTGF/CCN2) in serum is an indicator of fibrogenic progression and malignant transformation in patients with chronic hepatitis B infection. Clinica Chimica Acta. 2013; 421:126-131.

56. Wang GB, Zhou XY, Yuan T, Xie J, Guo LP, Gao N and Wang $X Q$. Significance of serum connective tissue growth factor in patients with hepatocellular carcinoma and relationship with angiogenesis. World J Surg. 2010; 34:2411-2417.

57. Gressner OA, Fang M, Li H, Lu LG, Gressner AM and 
Gao CF. Connective tissue growth factor (CTGF/CCN2) in serum is an indicator of fibrogenic progression and malignant transformation in patients with chronic hepatitis B infection. Clin Chim Acta. 2013; 421:126-131.

58. Qin LX. Inflammatory immune responses in tumor microenvironment and metastasis of hepatocellular carcinoma. Cancer Microenviron. 2012; 5:203-209.

59. Divella R, Mazzocca A, Gadaleta C, Simone G, Paradiso A, Quaranta $M$ and Daniele A. Influence of plasminogen activator inhibitor-1 (SERPINE1) 4G/5G polymorphism on circulating SERPINE-1 antigen expression in HCC associated with viral infection. Cancer Genomics Proteomics. 2012; 9:193-198.

60. Shin JY, Hur W, Wang JS, Jang JW, Kim CW, Bae SH, Jang SK, Yang SH, Sung YC, Kwon OJ and Yoon SK. $\mathrm{HCV}$ core protein promotes liver fibrogenesis via upregulation of CTGF with TGF-beta1. Exp Mol Med. 2005; 37:138-145.

61. Martin-Vilchez S, Sanz-Cameno P, Rodriguez-Munoz Y, Majano PL, Molina-Jimenez F, Lopez-Cabrera M, MorenoOtero R and Lara-Pezzi E. The hepatitis B virus $\mathrm{X}$ protein induces paracrine activation of human hepatic stellate cells. Hepatology. 2008; 47:1872-1883.

62. Bian Z, Peng Y, You Z, Wang Q, Miao Q, Liu Y, Han X, Qiu D, Li Z and Ma X. CCN1 expression in hepatocytes contributes to macrophage infiltration in nonalcoholic fatty liver disease in mice. J Lipid Res. 2013; 54:44-54.

63. Kular L, Pakradouni J, Kitabgi P, Laurent M and Martinerie C. The CCN family: a new class of inflammation modulators? Biochimie. 2011; 93:377-388.

64. Muromachi K, Kamio N, Narita T, Annen-Kamio M, Sugiya $\mathrm{H}$ and Matsushima K. MMP-3 provokes CTGF/ CCN2 production independently of protease activity and dependently on dynamin-related endocytosis, which contributes to human dental pulp cell migration. J Cell Biochem. 2012; 113:1348-1358.

65. Sarkissyan S, Sarkissyan M, Wu Y, Cardenas J, Koeffler HP and Vadgama JV. IGF-1 regulates Cyr61 induced breast cancer cell proliferation and invasion. PLoS One. 2014; 9:e103534.

66. Koga K, Yokoi H, Mori K, Kasahara M, Kuwabara T, Imamaki H, Ishii A, Mori KP, Kato Y, Ohno S, Toda N, Saleem MA, Sugawara A, Nakao K, Yanagita M and Mukoyama M. MicroRNA-26a inhibits TGF-beta-induced extracellular matrix protein expression in podocytes by targeting CTGF and is downregulated in diabetic nephropathy. Diabetologia. 2015; 58:2169-2180.

67. Tran CM, Smith HE, Symes A, Rittie L, Perbal B, Shapiro IM and Risbud MV. Transforming growth factor beta controls CCN3 expression in nucleus pulposus cells of the intervertebral disc. Arthritis Rheum. 2011; 63:3022-3031.

68. Maeda A, Ono M, Holmbeck K, Li L, Kilts TM, Kram V, Noonan ML, Yoshioka Y, McNerny EM, Tantillo MA, Kohn DH, Lyons KM, Robey PG and Young MF. WNT1- induced Secreted Protein-1 (WISP1), a Novel Regulator of Bone Turnover and Wnt Signaling. J Biol Chem. 2015; 290:14004-14018.

69. Chowdhury S, Wang X, Srikant CB, Li Q, Fu M, Gong YJ, Ning G and Liu JL. IGF-I stimulates CCN5/WISP2 gene expression in pancreatic beta-cells, which promotes cell proliferation and survival against streptozotocin. Endocrinology. 2014; 155:1629-1642.

70. Bai T, Chen CC and Lau LF. Matricellular protein CCN1 activates a proinflammatory genetic program in murine macrophages. J Immunol. 2010; 184:3223-3232.

71. Lin J, Zhou Z, Huo R, Xiao L, Ouyang G, Wang L, Sun Y, Shen B, Li D and Li N. Cyr61 induces IL-6 production by fibroblast-like synoviocytes promoting Th17 differentiation in rheumatoid arthritis. J Immunol. 2012; 188:5776-5784.

72. Lin MT, Zuon CY, Chang CC, Chen ST, Chen CP, Lin BR, Wang MY, Jeng YM, Chang KJ, Lee PH, Chen WJ and Kuo ML. Cyr61 induces gastric cancer cell motility/ invasion via activation of the integrin/nuclear factorkappaB/cyclooxygenase-2 signaling pathway. Clin Cancer Res. 2005; 11:5809-5820.

73. Lin BR, Chang CC, Chen LR, Wu MH, Wang MY, Kuo IH, Chu CY, Chang KJ, Lee PH, Chen WJ, Kuo ML and Lin MT. Cysteine-rich 61 (CCN1) enhances chemotactic migration, transendothelial cell migration, and intravasation by concomitantly up-regulating chemokine receptor 1 and 2. Mol Cancer Res. 2007; 5:1111-1123.

74. Sanchez-Lopez E, Rayego S, Rodrigues-Diez R, Rodriguez JS, Rodriguez-Vita J, Carvajal G, Aroeira LS, Selgas R, Mezzano SA, Ortiz A, Egido J and Ruiz-Ortega M. CTGF promotes inflammatory cell infiltration of the renal interstitium by activating NF-kappaB. J Am Soc Nephrol. 2009; 20:1513-1526.

75. Karger A, Fitzner B, Brock P, Sparmann G, Emmrich J, Liebe S and Jaster R. Molecular insights into connective tissue growth factor action in rat pancreatic stellate cells. Cellular Signalling. 2008; 20:1865-1872.

76. Wang X, McLennan SV, Allen TJ and Twigg SM. Regulation of pro-inflammatory and pro-fibrotic factors by CCN2/CTGF in H9c2 cardiomyocytes. J Cell Commun Signal. 2010; 4:15-23.

77. Wu SH, Lu C, Dong L and Chen ZQ. Signal transduction involved in CTGF-induced production of chemokines in mesangial cells. Growth Factors. 2008; 26:192-200.

78. Le Dreau G, Kular L, Nicot AB, Calmel C, MelikParsadaniantz S, Kitabgi P, Laurent M and Martinerie C. NOV/CCN3 upregulates CCL2 and CXCL1 expression in astrocytes through beta1 and beta5 integrins. Glia. 2010; 58:1510-1521.

79. Soon LL, Yie TA, Shvarts A, Levine AJ, Su F and TchouWong KM. Overexpression of WISP-1 down-regulated motility and invasion of lung cancer cells through inhibition of Rac activation. J Biol Chem. 2003; 278:11465-11470.

80. Lake AC and Castellot JJ, Jr. CCN5 modulates the 
antiproliferative effect of heparin and regulates cell motility in vascular smooth muscle cells. Cell Commun Signal. $2003 ; 1: 5$.

81. Chen CC and Lau LF. Deadly liaisons: fatal attraction between $\mathrm{CCN}$ matricellular proteins and the tumor necrosis factor family of cytokines. J Cell Commun Signal. 2010; 4:63-69.

82. Franzen CA, Chen CC, Todorovic V, Juric V, Monzon RI and Lau LF. Matrix Protein CCN1 Is Critical for Prostate Carcinoma Cell Proliferation and TRAIL-Induced Apoptosis. Molecular Cancer Research. 2009; 7:1045-1055.

83. Abreu JG, Ketpura NI, Reversade B and De Robertis EM. Connective-tissue growth factor (CTGF) modulates cell signalling by BMP and TGF-beta. Nat Cell Biol. 2002; 4:599-604.

84. Mori T, Kawara S, Shinozaki M, Hayashi N, Kakinuma T, Igarashi A, Takigawa M, Nakanishi $\mathrm{T}$ and Takehara $\mathrm{K}$. Role and interaction of connective tissue growth factor with transforming growth factor-beta in persistent fibrosis: A mouse fibrosis model. J Cell Physiol. 1999; 181:153-159.

85. Venkatachalam K, Venkatesan B, Valente AJ, Melby PC, Nandish S, Reusch JE, Clark RA and Chandrasekar B. WISP1, a pro-mitogenic, pro-survival factor, mediates tumor necrosis factor-alpha (TNF-alpha)-stimulated cardiac fibroblast proliferation but inhibits TNF-alpha-induced cardiomyocyte death. J Biol Chem. 2009; 284:1441414427.

86. Bai T, Chen CC and Lau LF. Matricellular Protein CCN1 Activates a Proinflammatory Genetic Program in Murine Macrophages. Journal of Immunology. 2010; 184:32233232.

87. Grote K, Salguero G, Ballmaier M, Dangers M, Drexler $\mathrm{H}$ and Schieffer $\mathrm{B}$. The angiogenic factor $\mathrm{CCN} 1$ promotes adhesion and migration of circulating CD34(+) progenitor cells: potential role in angiogenesis and endothelial regeneration. Blood. 2007; 110:877-885.

88. Tanaka S, Sugimachi K, Saeki H, Kinoshita J, Ohga T, Shimada M, Maehara Y and Sugimachi K. A novel variant of WISP1 lacking a Von Willebrand type C module overexpressed in scirrhous gastric carcinoma. Oncogene. 2001; 20:5525-5532.

89. Huang W, Zhang Y, Varambally S, Chinnaiyan AM, Banerjee M, Merajver SD and Kleer CG. Inhibition of CCN6 (Wnt-1-induced signaling protein 3) down-regulates E-cadherin in the breast epithelium through induction of snail and ZEB1. Am J Pathol. 2008; 172:893-904.

90. Mazzocca A, Fransvea E, Dituri F, Lupo L, Antonaci S and Giannelli G. Down-regulation of connective tissue growth factor by inhibition of transforming growth factor beta blocks the tumor-stroma cross-talk and tumor progression in hepatocellular carcinoma. Hepatology. 2010; 51:523534.

91. Rani P, Pal D, Hegde RR and Hashim SR. Acetamides: chemotherapeutic agents for inflammation-associated cancers. J Chemother. 2015:1973947815Y0000000060.

92. Yan M and Jurasz P. The role of platelets in the tumor microenvironment: From solid tumors to leukemia. Biochim Biophys Acta. 2015.

93. Cohen EN, Gao H, Anfossi S, Mego M, Reddy NG, Debeb B, Giordano A, Tin S, Wu Q, Garza RJ, Cristofanilli M, Mani SA, Croix DA, Ueno NT, Woodward WA, Luthra R, et al. Inflammation Mediated Metastasis: Immune Induced Epithelial-To-Mesenchymal Transition in Inflammatory Breast Cancer Cells. PLoS One. 2015; 10:e0132710.

94. Yoshimura T, Liu MY, Chen X, Li LZ and Wang JM. Crosstalk between tumor cells and macrophages in stroma renders tumor cells as the primary source of MCP-1/CCL2 in Lewis lung carcinoma. Frontiers in Immunology. 2015; $6: 332$.

95. Giannelli G, Rani B, Dituri F, Cao Y and Palasciano G. Moving towards personalised therapy in patients with hepatocellular carcinoma: the role of the microenvironment. Gut. 2014; 63:1668-1676.

96. Lobel M, Bauer S, Meisel C, Eisenreich A, Kudernatsch R, Tank J, Rauch U, Kuhl U, Schultheiss HP, Volk HD, Poller $\mathrm{W}$ and Scheibenbogen C. CCN1: a novel inflammationregulated biphasic immune cell migration modulator. Cellular and Molecular Life Sciences. 2012; 69:3101-3113.

97. Chen PC, Cheng HC, Wang J, Wang SW, Tai HC, Lin CW and Tang CH. Prostate cancer-derived CCN3 induces M2 macrophage infiltration and contributes to angiogenesis in prostate cancer microenvironment. Oncotarget. 2014; 5:1595-1608. Doi: 10.18632/oncotarget.1570.

98. Kim GJ, Rhee H, Yoo JE, Ko JE, Lee JS, Kim H, Choi JS and Park YN. Increased expression of CCN2, epithelial membrane antigen, and fibroblast activation protein in hepatocellular carcinoma with fibrous stroma showing aggressive behavior. PLoS One. 2014; 9:e105094.

99. Xiang ZL, Zeng ZC, Fan J, Tang ZY and Zeng HY. Expression of connective tissue growth factor and interleukin-11 in intratumoral tissue is associated with poor survival after curative resection of hepatocellular carcinoma. Molecular Biology Reports. 2012; 39:60016006.

100. Zhang KZ, Zhang QB, Sun HC, Ao JY, Chai ZT, Zhu XD, Lu L, Zhang YY, Bu Y, Kong LQ and Tang ZY. Arsenic trioxide induces differentiation of CD133+ hepatocellular carcinoma cells and prolongs posthepatectomy survival by targeting GLI1 expression in a mouse model. J Hematol Oncol. 2014; 7:28.

101. Li X, Fang P, Mai J, Choi ET, Wang H and Yang XF. Targeting mitochondrial reactive oxygen species as novel therapy for inflammatory diseases and cancers. J Hematol Oncol. 2013; 6:19.

102. Mah WC and Lee CG. DNA methylation: potential biomarker in Hepatocellular Carcinoma. Biomark Res. 2014; $2: 5$.

103. Smith AD, Roda D and Yap TA. Strategies for modern 
biomarker and drug development in oncology. J Hematol Oncol. 2014; 7:70.

104. Sliwkowski MX and Mellman I. Antibody therapeutics in cancer. Science. 2013; 341:1192-1198.

105. Brower V. Checkpoint blockade immunotherapy for cancer comes of age. J Natl Cancer Inst. 2015; 107.

106. Topalian SL, Hodi FS, Brahmer JR, Gettinger SN, Smith DC, McDermott DF, Powderly JD, Carvajal RD, Sosman JA, Atkins MB, Leming PD, Spigel DR, Antonia SJ, Horn L, Drake CG, Pardoll DM, et al. Safety, activity, and immune correlates of anti-PD-1 antibody in cancer. N Engl J Med. 2012; 366:2443-2454.

107. Bruix J, Gores GJ and Mazzaferro V. Hepatocellular carcinoma: clinical frontiers and perspectives. Gut. 2014; 63:844-855.

108. Joyce JA and Fearon DT. T cell exclusion, immune privilege, and the tumor microenvironment. Science. 2015; 348:74-80.

109. Dhar A and Ray A. The CCN family proteins in carcinogenesis. Exp Oncol. 2010; 32:2-9.

110. Heestand GM, Pipas JM, Valone F, McMullen AD, Gadea P, Williams D, Zhong M, Neff T, Fisher GA and Koong A. A phase I trial of the monoclonal antibody FG-3019 to connective tissue growth factor (CTGF) in locally advanced or metastatic pancreatic cancer. Journal of Clinical Oncology. 2011; 29.

111. Adler SG, Schwartz S, Williams ME, Arauz-Pacheco C, Bolton WK, Lee T, Li D, Neff TB, Urquilla PR and Sewell KL. Phase 1 study of anti-CTGF monoclonal antibody in patients with diabetes and microalbuminuria. Clin J Am Soc Nephrol. 2010; 5:1420-1428.

112. Neesse A, Frese KK, Bapiro TE, Nakagawa T, Sternlicht MD, Seeley TW, Pilarsky C, Jodrell DI, Spong SM and Tuveson DA. CTGF antagonism with mAb FG-3019 enhances chemotherapy response without increasing drug delivery in murine ductal pancreas cancer. Proceedings of the National Academy of Sciences of the United States of America. 2013; 110:12325-12330.

113. Finger EC, Cheng CF, Williams TR, Rankin EB, Bedogni B, Tachiki L, Spong S, Giaccia AJ and Powell MB. CTGF is a therapeutic target for metastatic melanoma. Oncogene. 2014; 33:1093-1100.

114. Dimou AT, Syrigos KN and Saif MW. Novel agents in the management of pancreatic adenocarcinoma: phase I studies. Highlights from the "2011 ASCO Gastrointestinal Cancers Symposium". San Francisco, CA, USA. January 20-22, 2011. JOP. 2011; 12:114-116.

115. Feng P, Wang B and Ren EC. Cyr61/CCN1 is a tumor suppressor in human hepatocellular carcinoma and involved in DNA damage response. Int J Biochem Cell Biol. 2008; 40:98-109.

116. Wang B, Ren J, Ooi LL, Chong SS and Lee CG. Dinucleotide repeats negatively modulate the promoter activity of Cyr61 and is unstable in hepatocellular carcinoma patients. Oncogene. 2005; 24:3999-4008. 